\title{
An assessment of inter-professional knowledge of Nigerian pharmacists on topical dosage specificity; and the effects of electro-physical agents on drugs
}

\author{
Onigbinde Ayodele Teslim ${ }^{1,}$, , Ojo Ayodele Mojisola ${ }^{1}$, Bamitale Kayode Dominion ${ }^{2}$, Wiesener Trond ${ }^{3}$ \\ ${ }^{1}$ Medical Rehabilitation Department, Faculty of Basic Medical Sciences, Obafemi Awolowo University, Ile-ife, Osun State, Nigeria \\ ${ }^{2}$ Department of Medical Pharmacology and Therapeutics, Faculty of Basic Medical Sciences, Obafemi Awolowo University, Ile-ife, Osun \\ State, Nigeria \\ ${ }^{3}$ Department of Physiotherapy, University of Tromso, Tromso, Norway
}

Email address:

ayotesonigbinde@yahoo.co.uk (A. T. Onigbinde)

\section{To cite this article:}

Onigbinde Ayodele Teslim, Ojo Ayodele Mojisola, Bamitale Kayode D. S., Wiesener Trond. An Assessment of Inter-Professional Knowledge of Nigerian Pharmacists on Topical Dosage Specificity; and the Effects of Electro-Physical Agents on Drugs. American Journal of Health Research. Special Issue: Supplementary Prescribing in Nigeria: A Needy Concept to Promote Clinical Physiotherapy Practice.

Vol. 2, No. 5-1, 2014, pp. 17-21. doi: 10.11648/j.ajhr.s.2014020501.14

\begin{abstract}
There is need for Inter-professional education and collaboration among health professionals in order to avoid misconceptions and under-utilization. The primary aims of this study were to investigate the familiarity of Nigerian pharmacists with Finger Tip Unit (FTU) as a means of quantifying dose for topical medications; and also assess their knowledge on the effects of electro-physical modalities on drugs. A structured questionnaire was used to obtain information from 110 pharmacists. Descriptive statistics and Non- parametric inferential statistics were used to analyze the data. The result showed that only 48 respondents (43.6\%) were familiar with Finger Tip unit (FTU). There was no significant difference in the number of respondents who were familiar and those unfamiliar with FTU. Among 84 respondents who answered questions on active ingredients, a total of $60.7 \%$ were rated between good and excellent in knowledge. The result of the Chi-square test showed that a significant number of respondents agreed that exercise can increase kinetic molecular movement of drugs, and that the effect of exercise depends on the type of drugs while drug absorption can also be increased by external massage $(\mathrm{P}<$ 0.001). This study concluded that pharmacists have good knowledge of active ingredients in the selected drugs. Also, about half the respondents knew the effects of physiotherapy agents on drugs and a moderate number were familiar with the use of FTU as a means of quantifying dose for topical medications.
\end{abstract}

Keywords: Inter-Professional Knowledge, Pharmacists, Physiotherapy, Electro-Physical Modalities

\section{Introduction}

Knowledge is a fluid mix of framed experience, contextual information, values and expert insight that provides a framework for evaluating and incorporating new experiences and information [1]. It refers to what is known through study or experience and it is synonymous with information, learning, erudition, lore and scholarship; and it also extends to awareness, consciousness, or familiarity gained by experience or learning [2]. North American Nursing Diagnosis Association viewed knowledge as the absence or deficiency of cognitive information related to a specific topic [3].

Inter-professional education and collaboration interventions aims at improving inter-professional relationship; facilitate knowledge translation and also improve evidence-based practice [4]. Inter-professional learning (IPL) is when two or more professions learn with, from and about each other in order to improve collaboration and the quality of care [5]. The concept is not new because over the past 10 years it has become an inevitable part of most pre- and post-registration health and social care professional programmes throughout the United Kingdom [6, 7]. Also, World Health Organisation is an advocator for interprofessional approach to learning globally [7, 8].

Physiotherapy profession remains the major focus in the centre of rehabilitative care; hence it is becoming increasingly important for other health professions to gain 
more knowledge about it. Jackson reported that lack of knowledge or poor knowledge about a profession may lead to misconceptions about the profession and may also lead to inter-professional conflicts, and that good awareness of the role of physiotherapy in health care delivery may influence its use and this will probably reduce under-utilization [9]. Inter-professional education and collaborations among health professionals, requires continuous interaction, coordinated efforts, and knowledge sharing among themselves [10]. Currently, in the health team, there is limited understanding of collaborations [11].

There is increasing interest in pharmacotherapy among physiotherapists and this may necessitate collaboration with pharmacists. Pharmaco-physical therapy and Rehabilitative pharmaco-therapeutics are specialties in physiotherapy which involves the use of pharmacotherapy (therapeutic application of drugs) in conjunction with physiotherapy in the treatment of medical conditions [12].

Inter-professional knowledge of topical dosage prescription is an area where strong collaboration is required between pharmacists and physiotherapists to ensure accurate dosage specificity for patients. The Fingertip Unit (FTU) is the adopted method for dosages of topical drugs because topical prescription unlike other dosage forms is generally considered an inaccurate procedure but little attention is given to ensure specificity and this is a potential source of side-effects and treatment failure [13 - 15]. Moreover, it is uncertain if pharmacists have adequate knowledge about the roles of physiotherapists in transdermal application of therapeutic medications. All these necessitated this study.

The objectives of this study were to assess the knowledge of Nigerian pharmacists on physiotherapy procedures involving the use of drugs and also determine their knowledge on the effects of electro-physical modalities, exercise and massage on drugs; and to assess their familiarity with the use of Finger Tip Unit (FTU) as dosage tool for topical medications.

\section{Materials and Method}

\subsection{Subjects and Sampling Technique}

One hundred and ten (110) practising pharmacists participated in the study. They were sample of convenience from purposively selected hospitals and drug companies.

\subsection{Instrumentation}

The instrument used in obtaining information was a slight modification of the questionnaire used by Onigbinde et al, [16]. The questionnaire sought for demographics and academic- related data, responsibility of authorities to provide information on relevant topical medications to physiotherapists, knowledge about FTU, Dosage card, iontophoresis and phonophoresis and knowledge of dominant ions in some relevant topical drugs to physiotherapy. There are 8 positive opinion statements on effects of electrophysical modalities, therapeutic exercises and massage on drugs. The respondents were expected to choose level of agreement for each opinion statement (Agreed, Disagreed and undecided).

\subsection{Research Design}

The study was a cross sectional exploratory survey study.

\subsection{Procedure}

The Research and Ethics Committee of the Institute of Public Health, Obafemi Awolowo University Ile-Ife, Osun state, Nigeria granted approval for the study. Approval was also given by the authorities of the different work settings. The study took into consideration the willingness of the participants to answer the questionnaire and return it immediately. This was necessary to prevent the participants from interacting and cheating. The respondents were expected to define the words: iontophoresis and phonophoresis. Each correct definition was allotted a maximum score of 2. On knowledge of active ingredients, the answers provided were marked and graded. Six (6) was the maximum score allotted for correct identification of ionic charges on the checklist of selected topical medications (Lidocaine, Methyl salicylate, Gentamicin sulphate, Glucosamine sulphate, Diclofenac sodium and Piroxicam). A consensus rating was done using the method of Onigbinde et al [16] and the respondents overall score were graded thus (Table 1):

Table 1. Range of scores

\begin{tabular}{ll}
\hline Range of Scores & Grades \\
\hline $0-1$ & Very Poor \\
$1-2$ & Poor \\
$2-3$ & Fair \\
$3-4$ & Good \\
$4-5$ & Very Good \\
$5-6$ & Excellent \\
\hline
\end{tabular}

\subsection{Data Analysis}

For the purpose of analysis, those who chose undecided were merged with those who disagreed; collapsing the agreement options into agreed and disagreed. The data were analyzed using descriptive statistics and Non- parametric inferential statistics of Chi-square test. Statistical package for social sciences software (SPSS Inc., Chicago, and U.S.A) was used.

\section{Results}

Most respondents (46 [41.4\%]) were within the age range of 20 - 30 years, $24(21.6 \%)$ and $15(13.5 \%)$ were within the age ranges of $31-40$ and $41-50$ years respectively (only 85 respondents provided information on their ages). Sixty-six $(60 \%)$ respondents had Bachelor's degree while10 respondents $(9.1 \%)$ had Doctorate degree in relevant fields of pharmacy. Forty-six (41.8\%) respondents were practicing in Teaching hospitals. The percentage distribution of qualifications and work settings are represented in figures $1 \mathrm{a}$ 
and b. Only fifty (45.5\%) respondents were familiar with iontophoresis and $39(35.5 \%)$ were familiar with phonophoresis.

The result of the Chi square showed that there was no significant difference in the number respondents who were familiar and those who were unfamiliar with iontophoresis. However, there was significant difference in number of those familiar and those unfamiliar with procedure of phonophoresis $\left(\mathrm{X}^{2}=5.65, \mathrm{P}<0.02\right)$, (Figure 2). Respondents who were familiar with iontophoresis scored $1.76 \pm 0.61$ while those familiar with phonophoresis scored $1.81 \pm 0.53$ out of a maximum score of 2 allot-able in the definition of the two procedures. The result showed that $48(43.6 \%)$ respondents were familiar with the use Finger Tip unit (FTU). There was no significant difference in the number of respondents who were familiar and those unfamiliar with FTU.

Also, $68(61.8 \%)$ respondents were aware that dosage card could be used in quantifying dose of topical medications. There was significant difference in the number of respondents who were familiar and those unfamiliar with the use of dosage cards $\left(\mathrm{X}^{2}=10.57, \mathrm{P}<0.001\right)$, (Table 2). Also, $84(73.36 \%)$ respondents attempted the questions on

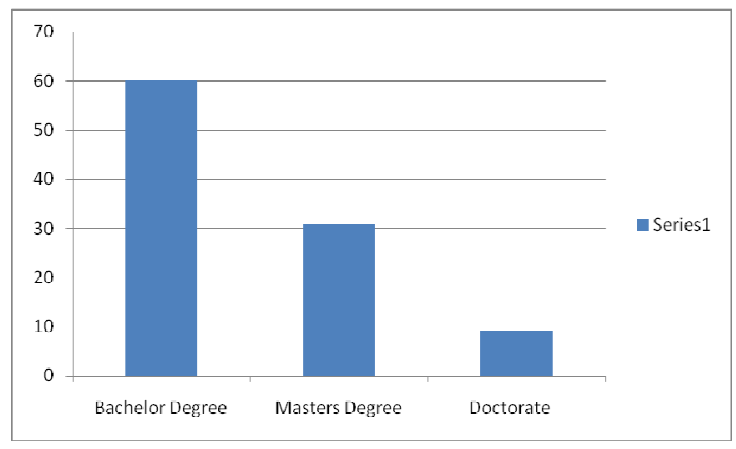

Figure 1a. Qualifications of participants

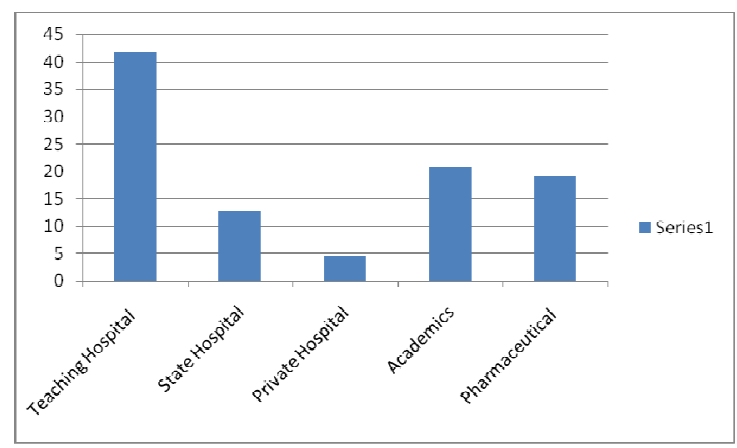

Figure 1b. Work settings of participants

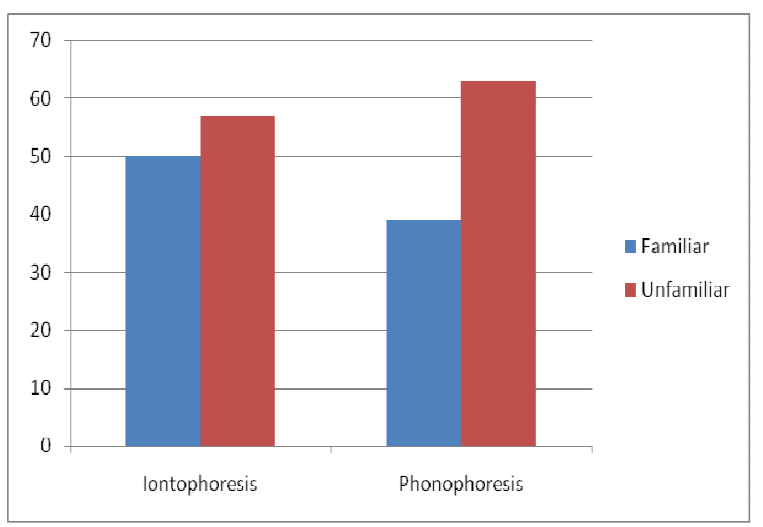

Figure 2. Familiarity with iontophoresis and phonophoresis

Table 2. Familiarity with FTU and dosage cards

\begin{tabular}{llllll}
\hline Variables & Options & Freq & $\mathbf{\%}$ & X2 & P \\
\hline \multirow{2}{*}{ Fingertip Unit: } & YES & 48 & 43.6 & & \\
& NO & 57 & 51.8 & 0.77 & 0.38 \\
\multirow{2}{*}{ Dosage Card: } & YES & 68 & 61.8 & & \\
& NO & 35 & 31.8 & 10.57 & 0.001 \\
\hline
\end{tabular}

Table 3. Knowledge levels of pharmacists on active ingredients in selected drugs and its association with work setting.

\begin{tabular}{|c|c|c|c|c|c|c|c|c|}
\hline \multicolumn{9}{|l|}{ Frequency $(N=84)$} \\
\hline Settings & V. poor & Poor & Fair & Good & V. good & Excellent & $\mathbf{X 2}$ & $\mathbf{P}$ \\
\hline State hospital & 0 & 2 & 0 & 0 & 2 & 0 & & \\
\hline Teaching hospital & 3 & 0 & 1 & 3 & 0 & 0 & & \\
\hline Academics & 4 & 7 & 5 & 7 & 5 & 5 & & \\
\hline Pharm. Company & 5 & 2 & 3 & 1 & 5 & 4 & & \\
\hline Private & 0 & 0 & 1 & 6 & 9 & 4 & 59.90 & 0.002 \\
\hline Column total & 12 & 11 & 10 & 17 & 21 & 13 & & \\
\hline
\end{tabular}

Table 4. Knowledge of pharmacists on the effects of elctro-physical modalities, exercise and massage on drugs

\begin{tabular}{llll}
\hline Variables & Agreed N (\%) & Disagreed N (\%) & X2 \\
\hline Exercise increases kinetic movements of drugs & $94(88.7)$ & $12(11.3)$ & 109.00 \\
Effect of exercise depends on the type of drug & $77(77)$ & $23(23.0)$ & 109.00 \\
External massage increases absorption & $91(85.8)$ & $15(14.1)$ & 109.00 \\
Physiotherapy affects bio-availability & $75(72.8)$ & $28(27.2)$ & 7.011 \\
Thermal agents increase regional blood flow & $37(36.3)$ & $65(63.7)$ & 60.87 \\
Exercise affects absorption at injection sites & $24(23.1)$ & $80(76.9)$ & 103.00 \\
Antibiotic application through iontophoresis & $23(23.5)$ & $75(76.5)$ & 0.001 \\
Exercise alters cardiovascular effects & $71(68.3)$ & $33(31.7)$ & 0.001 \\
\hline
\end{tabular}


Knowledge of active ingredients in topical drugs, out of the maximum score of 6 allotted; the participants had a mean score of $3.70 \pm 1.75$. The levels of knowledge of active ingredients are presented in Table 3. There was significant association between work settings and knowledge of active ingredients in the selected drugs $\left(\mathrm{X}^{2}=59.90, \mathrm{P}<0.002\right)$

The number of respondents who agreed that exercise can increase kinetic molecular movement of drugs was significantly higher than those who disagreed $\left(\mathrm{X}^{2}=109.00 ; \mathrm{P}\right.$ $<0.001)$ and similar trend was observed for other positive opinion statements excluding opinion on the effect of thermal agents, effect of exercise at injection sites and application of antibiotics (Table 4).

\section{Discussion}

Knowledge is information that changes something or somebody - either by becoming more knowledge-able for actions, or by making an individual (or an institution) capable of different or more effective action [17]. Inter-professional education creates a good learning environment for health workers to improve spirit required for teamwork in practice [18].

Less than half of the pharmacists were familiar with iontophoresis but a significant proportion of respondents were unfamiliar with the procedure of phonophoresis. Although, the knowledge levels of understanding what electromotive administration (iontophoresis and phonophoresis) are were good. It is noteworthy, that $23.6 \%$ respondents did not attempt questions on the procedures which also implied lacked of knowledge. Among the 84 respondents; $60.7 \%$ were rated between good and excellent in their level of knowledge. We observed significant association between work settings and knowledge of active ingredients. Most respondents in academic, private and pharmaceutical settings had a better knowledge compared to those in the hospitals. This may be attributed to regular and continuous research work which is a routine in academic institutions and pharmaceutical companies but we could only attribute that of private setting to individual quest for knowledge. In Australia, most pharmacists provide education to hospital staff and are members on hospital committees; and they also perform clinical duties including medication chart review and counselling [19]. These responsibilities might be tasking them to seek for adequate knowledge.

There is likelihood of in-discrepancies in the dosage being prescribed for patients as almost half of the pharmacists were unfamiliar with FTU which is a standard measure of quantifying topical medications [13-15, 20]. They must have been using the principle of 'apply generously'. They were familiar with dosage cards but dosage cards are not readily available for most topical medications. The FTU is simple, and it is easily applied by either the patients or care givers.

A significant proportion of respondents agreed that exercise could affect kinetic molecular movements of drugs and that the effect also depends on the type of drugs. The bioavailability of drug is increased when exercising. There is increase in tissue heat which subsequently leads to an increase in kinetic molecular movement of the drug [21]. Although, there appears to be conflicting reports on the effect of exercises on bioavailability but the differences have been notably due to the type of drugs, intensity, duration and type of exercises [22 - 24]. Khazaenia reported that exercise did not have substantial effect on the absorption of orally administered drugs but can aid absorption from intramuscular, subcutaneous, transdermal and inhalation site [22]. Therapeutic exercises affect pharmacokinetic variables of drugs resulting in either positive or negative influences and this depends on factors such as bouts, repetitions, frequency of exercises and excretory organs [25].

Similarly, a significant proportion of respondents agreed that absorption of drugs can be increased by external massage. Mattuci-Cerinic and Casini reported that exercises increase the absorption of some drugs [26]. Similarly, most respondents agreed that bioavailability can also be affected by physiotherapy modalities. There was lack of knowledge on the effects of thermal agents and exercise on regional blood flow; and injection sites as most respondents disagreed with the positive opinion statements. Thermal agents and electrical stimulation of muscles increase regional blood flow, thus increasing drug delivery to systemic circulation and adjacent tissues at site of application [21]. Furthermore, there was lack of knowledge on electromotive administration of antibiotics. Several studies had administered antibiotics through iontophoresis especially for management of skin ulcers [27]. Generally, out of the 8 listed positive opinion statements, a significant proportion agreed on 4 and disagreed on another 4 . We considered their knowledge on the effects of physiotherapy agents on drugs to be fairly good. There is a need for inter-professional education to be included in students' training curricula for all relevant medical fields while continuing education program should be organized for all qualified health workers. [28].

We concluded that most pharmacists in this study have good knowledge of active ingredients in the selected drugs. They also have fairly good knowledge of the effects of electro-physical modalities, exercise and massage on drugs. Most respondents were also more familiar with dosage cards than FTU in prescribing dose for topical medications.

\section{References}

[1] Davenport, T., Prusak, L (1998). Working Knowledge. Harvard Business School Press: Boston, MA. www.harvardbusinessschool.org. Accessed on $13^{\text {th }}$ June 2013.

[2] Farlex, The Free Dictionary (2013). Knowledge. http://www.thefreedictionary. com/ knowledge. Accessed on $13^{\text {th }}$ June 2013.

[3] Miller-Keane (2003). Encyclopedia and Dictionary of Medicine, Nursing, and Allied Health, Seventh Edition. Saunders, an imprint of Elsevier. 
[4] 14] Zwarenstein M, Reeves S. Knowledge translation and inter-professional collaboration: Where the rubber of evidence-based care hits the road of teamwork. J Contin. Educ. Health Prof. 2006 Winter; 26 (1):46-54.

[5] CAIPE (1997). Inter-professional education - a definition. CAIPE Bulletin, 13, 19

[6] Barr, H. (2002). Inter-professional education today, yesterday, and tomorrow: A review. The Learning and Teaching Support Network for Health Sciences \& Practice from The UK Centre for the Advancement of Inter-professional Education, 147.Retrieved December 30, 2008 from www.health.heacademy.ac.uk/publications/ occasionalpaper/ occp1 revised.pdf. Accessed on $14^{\text {th }}$ August 2013.

[7] The Knowledge Network (2013). Inter-professional Learning. http://www. knowledge. scot.nhs.uk/home/learning-andcpd/about-education-and-learning/interprofessionallearning.aspx. Accessed on $14^{\text {th }}$ August 2013.

[8] World Health Organisation (2010) Framework for Action on Inter-professional Education and Collaborative Practice. World Health Organisation. Accessed on $14^{\text {th }}$ August 2013.

[9] Jackson, D.A. 2004. Where is the physiotherapy profession going? Physiotherapy 22 (2): 400-455.

[10] American Speech-Language-Hearing Association, 2013). Inter-professional Education: Why is greater emphasis being placed on inter-professional education in health care? What impact will it have on the education of audiologists and speech-language pathologists? http://www.asha.org/academic/questions/InterprofessionalEducation/. Accessed on $14^{\text {th }}$ August 2013.

[11] Leggat, S. G. (2007). Effective healthcare teams require effective team members: Defining teamwork competencies. BMC Health Services Research, 7(17).

[12] Lawless Linda and Lastayo Paul (2011): Pharmacology for Physical Therapists; a publication. Wikipedia.com. Accessed on $14^{\text {th }}$ August 2013.

[13] Finlay A.Y, Edwards P.H, Harding K.G (1989): "Fingertip Unit" in dermatology: Lancet. Vol.11, Pg 155.

[14] Osborne J.E, Hutchison P.E (2002): Jeur Acad Dermatol Venereol. 16(4):367-373

[15] Castanedo-Cazares JP, Torres-Alvarez B, Martinez-Rodriguez A, Diaz-Rosales A, Moncada B. Analysis of the digital unit as reference measurement for the topical prescription in Mexico (in Spanish). Gac Med Mex 2006; 142: 35-38.

[16] Onigbinde A.T, Olaogun O.B, Iroghue K (2012): An evaluation of the knowledge level of Nigerian Physiotherapists on topical pharmacotherapy Hong Kong Physiotherapy Journal Vol. 1 Pgs. 1-7
[17] Drucker P.F (1989) in Andreas Seufert, Georg von Krogh, Andrea Bach, (1999) "Towards knowledge networking", Journal of Knowledge Management, Vol. 3 Iss: 3, pp.180 190

[18] Canadian Interprofessional Health Collaborative. (2007). Interprofessional education and core competencies: Literature review. Vancouver, Canada: Canadian Interprofessional Health Collaborative. Retrieved 29 January 2010 from: http://www.cihc.ca/files/ publications /CIHC_IPELitReview_May07.pdf. Accessed on $13^{\text {th }}$ June 2013.

[19] Moles R, Brien J, Benrimoj C. Factors influencing pharmaceutical service provision within NSW private hospitals. Australian Pharmacist 2004; 23: 238-43.

[20] Long C.C, Finlay A.Y (1991): The Fingertip Unit: a new practical measure. Clinical Experimental Dermatology, Vol.16. Pgs. 444-446

[21] Onigbinde A.Ts Adedoyin R.A Johnson O.E (2006): Effect of physical therapy interventions on pharmacokinetic variables: A preliminary review, Nigerian Journal of Medical Rehabilitation; Vol, 11, No 19, June, 1 -5.

[22] Khazaenia T, Ramsey A A, Tam Y K (2000): The effect of exercise on Pharmacokinetic of drugs. J Pharm Phram Sci. Sep- Dec; 3 (3): 292-302

[23] Sarwrymiowez M and Chock-spolly (1997). The effect of exercise on the pharmacokinetic of acetaminophen and acetyl salicylic acid. Annal Acad Med; 43, 57 - 66

[24] Dyke TM, Sams RA,Hinchiellif KW (1998). Intensitydependent effect of acute sub-maximal exercise on the pharmacokinetic of bromosulhalein in horses. Am J Vet Res, Nov; 59 (11): 1481 - 1487

[25] Onigbinde A.T, Oyerinde O, Talabi A.E, Obiyemi O.O, Ogunsakin E.A, Adesoye A.A, Sheu R.A, Oniyangi S.O, Orijajogun O.O (2009): Effect of therapeutic exercises on some selected drugs: Nigerian Journal of Medical Rehabilitation. Vol 14, No 1 and 2, issue no 22, 13 -17.

[26] Mutucci-Cerinic M, Casini A (1998): Ketoprofen vs ketofenamate in controlled double-blind study: evidence of tropical effectiveness in soft tissue rheumatic pain. Int J Clin Pharmacol Ress; Vol.8: Pgs. 157-160

[27] Onigbinde A.T, Olafimihan K.F, Ojuawo A et al (2010): Management of decubitus ulcer using Gentamicine sulphate iontophoresis: A case study. Accepted for publication The International Journal of Allied Health, Vol 9, No 1, $1-4$.

[28] Coster, S., Norman, I., Murrells, T., Kitchen, S., Meerabeau, E., Sooboodoo, E., \& d'Avray, L. (2008). Interprofessional attitudes amongst undergraduate students in the health professions: A longitudinal questionnaire survey. International Journal of Nursing Studies, 45, 1667-1681. 